\title{
DO THE COGNITIVE SKILLS OF SCHOOL DROPOUTS MATTER IN THE LABOR MARKET?
}

\author{
John H. Tyler \\ Richard J. Murnane \\ John B. Willett \\ Working Paper 7101 \\ http://www.nber.org/papers/w7101 \\ NATIONAL BUREAU OF ECONOMIC RESEARCH \\ 1050 Massachusetts Avenue \\ Cambridge, MA 02138 \\ April 1999
}

We gratefully acknowledge the support of the National Center for the Study of Adult Learning and Literacy (NCSALL) $^{* *}$ and the Rockefeller, Russell Sage, and Spencer Foundations.

** Work supported by NCSALL was supported under the Educational Research and Development Centers Program, Award Number R309B60002, as administered by the Office of Educational Research and Improvement/National Institute on Postsecondary Education, Libraries, and Lifelong Learning, U.S. Department of Education. The contents do not necessarily represent the positions or policies of the National Institute on Postsecondary Education, Libraries, and Lifelong Learning, the Office of Educational Research and Improvement, or the U.S. Department of Education, and you should not assume endorsement by the Federal Government. The views expressed herein are those of the authors and do not necessarily reflect the views of the National Bureau of Economic Research.

(0) 1999 by John H. Tyler, Richard J. Murnane, and John B. Willett. All rights reserved. Short sections of text, not to exceed two paragraphs, may be quoted without explicit permission provided that full credit, including ${ }^{\circ}$ notice, is given to the source. 
Do the Cognitive Skills of School Dropouts

Matter in the Labor Market?

John H. Tyler, Richard J. Murnane, and John B. Willett

NBER Working Paper No. 7101

April 1999

\section{ABSTRACT}

Does the U.S. labor market reward cognitive skill differences among high school dropouts, the members of the labor force with the least educational attainments? This paper reports the results of an exploration of this question, using a new data set that provides information on the universe of dropouts who last attempted the GED exams in Florida and New York between 1984 and 1990. The design of the sample reduces variation in unmeasured variables such as motivation that are correlated with cognitive skills. We examine the labor market returns to basic cognitive skills as measured by GED test scores. We explore whether the returns differ by gender and race. The results indicate quite large earnings returns to cognitive skills for both male and female dropouts, and for white and non-white dropouts. The earnings payoff to skills increases with age.

John H. Tyler

Box 1938

Brown University

Providence, RI 02912-1938

John_Tyler@Brown.EDU

John B. Willett

Harvard Graduate School of Education

6 Appian Way

Cambridge, MA 02138

willetjo@hugse1.harvard.edu
Richard J. Murnane

Harvard Graduate School of Education

6 Appian Way

Cambridge, MA 02138

and NBER

murnanri@hugse1.harvard.edu 


\section{Do the Cognitive Skills of School Dropouts Matter in the Labor Market?}

\section{Introduction}

Between 1979 and 1996 the median earnings of 25-34 year-old males who left school before obtaining a high school diploma fell by 30 percent; the corresponding figure for female dropouts is a 21 percent decline. Over this same period the earnings premium four-year college graduates received over the earnings of male dropouts increased from 60 percent to 133 percent. The primary explanation for these patterns is that the demand for unskilled workers declined relative to the demand for skilled workers (Gottschalk, 1997; Katz \& Murphy, 1992).

While the average cognitive skill level of school dropouts is quite low, there is considerable variation among dropouts in cognitive skill levels. One could argue that, in an economy in which cognitive skills are increasingly valued, differences in skills would translate into earnings differences for dropouts just as they do for workers with greater educational attainments. On the other hand, the economic trends that have depressed the average earnings of the less skilled may have relegated most young dropouts to entry level jobs where skills matter very little and consequently are not rewarded. This could be especially true for non-white male dropouts, whose earnings in 1996 averaged 28 percent less than those of white male dropouts. This paper reports evidence on the labor market payoff to cognitive skills for school dropouts, and whether the payoff differs by gender and race/ethnicity.

Several problems hamper attempts to explore the impact of cognitive skills on labor market performance. First, since the test scores that provide the measures of cognitive skills in most data sets are of no consequence to the test-takers, the scores may provide underestimates of true cognitive skills, especially for individuals who find test-taking distasteful. Second, the test scores may be correlated with unmeasured variables such as motivation levels which affect labor market performance. Consequently, correlations between test scores and labor market earnings may reflect the importance of unmeasured motivation, rather than the causal impact of cognitive skills. Third, many studies measure labor market performance by hourly wage. This excludes from the analysis those individuals who are unable to find work as a result of low cognitive skill levels. 
Finally, some data sets, such as the National Adult Literacy Survey, include only contemporaneous information on cognitive skills and wages. This makes it difficult to identify causation. It may be that individuals who obtain well paying jobs for reasons unrelated to cognitive skill levels receive training that results in relatively high skill levels.

We examine the returns to cognitive skills using a data set that responds to the problems listed above. This data set consists of information on a sample of individuals who dropped out of school and later attempted to acquire a General Educational Development (GED) credential. While this is not a random sample of all dropouts, data on these individuals do offer a number of advantages. First, our measure of skills for these individuals is their standing on the GED exams, a seven and one-half hour battery of exams covering mathematics, writing, reading, social studies, and science. The GED exams represent a high-stakes test for the members of our sample. As a result, we expect that individuals approach the tests with seriousness and effort, and hence scores on these exams better measure underlying true skills than test scores in other data sets. Second, all individuals in our data have exhibited a desire to obtain a GED, as evidenced by their willingness to prepare for and attempt the lengthy battery of tests. Consequently, there is probably less unmeasured variation in motivation among individuals in this data set than is the case among participants in other surveys. Third, we measure labor market performance by annual earnings. This allows us to include dropouts with zero earnings in our analysis sample. Finally, we measure labor market earnings five years after dropouts last attempted the GED exams. This reduces the problem of assessing the direction of causation of the correlation between test scores and earnings.

We discuss the unique nature of our data in the next section, and we turn to our methodology in Section 3. In Section 4 we present and discuss our results, and we show that skills do matter for young dropouts, white and nonwhite, male and female.

\section{Data}

We analyze data containing information on the universe of dropouts in New York and Florida who took the GED exams between 1986 and 1990 and were aged 16 to 21 when they last took these exams. The data released to us by the departments of education in these states contain 
basic demographic information and GED test scores. To obtain an outcome measure, we worked with the Social Security Administration (SSA) to merge the state GED data with Social Security taxable annual earnings via Social Security numbers. As detailed by Angrist (1997), SSA earnings data such as those released to us have a number of limitations. ${ }^{1}$ One important limitation is that for confidentiality reasons, the SSA does not release individual earnings to researchers. Rather, they release aggregated data based on directions supplied by the researcher. Because the SSA will only release aggregate data, we are only able identify individuals as "white, non-Hispanic" or as "other than white, non-Hispanic." For ease of exposition we call these two groups "whites" and "nonwhites."

SSA aggregation guidelines also preclude us from retaining continuous GED score information. As a result, we retain GED test score information in our data by constructing ten "score group" categories that reflect unique combinations of overall mean scores on the five tests in the GED battery and minimum scores out of the five tests. While the relationship between these score groups is not cardinal in nature, the score groups are ordinal and monotonic. Thus, a higher score group represents a higher mean score, a higher minimum score, or both, and hence, a higher level of measured skills. ${ }^{2}$ The construction of these GED test score groups is displayed in Figure 1 .

$<$ Figure 1 about here>

The rows in Figure 1 represent successively higher minimum score intervals. The minimum score intervals are 5 points at the bottom end of the range and 2 points at the upper end. The two columns in Figure 1 represent the two ranges of the mean score we use: less than a 45 mean score

\footnotetext{
${ }^{1}$ Limitations regarding top coding, covered occupations, and other aspects of the SSA earnings records are discussed by us in Tyler, Murnane, and Willett (1998). Our overall conclusion is that these limitations do not provide serious problems for this research.

${ }^{2}$ This is true except for the range around score groups 3 and 4. Individuals in score group 3 have lower mean scores than those in score group 4, but higher minimum scores (see Figure 1). Thus, it is not clear which group has higher overall skill levels.
} 
and a mean score of 45 or higher. We include in our models dichotomous indicators of 9 of the 10 score groups and interactions between each of the score group indicators and other variables of substantive interest.

The cells in our data are defined by state (Florida or New York), year-of-test (1986-1990), GED score group (1-10), gender, and race/ethnicity (white or nonwhite). For each cell the SSA released the mean earnings in the cell, the standard deviation of earnings, and the cell frequency.

$<$ Table 1 about here>

As indicated in Table 1, 46 percent of the individuals in the data set attempted the GED tests in Florida and 53 percent in New York. The proportion male is about the same in both states and is slightly higher than the proportion female. The sample from Florida is substantially more white than the sample from New York. The distribution across the GED score groups is similar in the two states, with Florida having a slightly higher percentage of dropouts scoring in the three highest score groups.

Table 2 provides information for males on mean annual earnings (in 1995 constant dollars ${ }^{3}$ ) five years after each cohort last took the GED exams. Table 3 provides the analogous information for females. ${ }^{4}$ The entries in these two tables show that the annual earnings of young dropouts are quite low, on average, regardless of the state or year. These low mean earnings suggest that young dropouts are either employed in very low wage jobs, are often without employment (i.e., their mean earnings are zero), or both.

${ }^{3}$ All earnings in the data are converted to 1995 constant dollars using the Consumer Price Index-All Urban Consumers (CPI-U) index.

${ }^{4}$ The lower unconditional mean earnings in New York, generally considered a high wage state relative to Florida, is at least in part due to the higher percentage of nonwhite dropouts in New York. In other data available to us, however, we observe that the lower New York mean earnings are also due to a higher presence of zeros in the cells, as the mean of positive earnings is higher in New York than Florida. 


\section{Statistical Analysis}

\section{Analytic Model}

The data we use to examine the returns to skills for our sample of young dropouts consist of 635 cells as described earlier. We are interested in $y_{i c}$, the true earnings of the $i_{t h}$ person in the $c_{t h}$ cell. However, as a result of the nature of the data released to us by the Social Security Administration, we only have a sample estimate of the mean earnings, $\mu_{c}$, in the $c_{t h}$ cell. We assume that $y_{i c}=\mu_{c}+\mathrm{w}_{i c}$ where $\mathrm{w}_{i c} \sim N\left(0,{ }^{2}\right)$.

We would like to examine the relationship between skills and earnings by fitting a series of models in which the dependent variable is the cell population mean earnings $\mu_{c}$, and the explanatory variables of primary interest are the GED score group and score group-demographic group interactions associated with individuals who make up the $c_{t h}$ cell. Our model is:

$$
\begin{aligned}
\mu_{c}= & \beta_{0}+\beta_{1} \text { female }_{c}+\beta_{2} \text { nonwhite }_{c}+\beta_{3} \text { state }_{c}+ \\
& \beta_{4}\left(\text { nonwhite }_{c} * \text { female }_{c}\right)+\beta_{5}\left(\text { nonwhite }_{c} * \text { state }_{c}\right)+ \\
& { }_{\mathbf{1}} \mathbf{s g}_{c}+{ }_{2}\left(\boldsymbol{s g}_{c} * \text { female }_{c}\right)+{ }_{3}\left(\boldsymbol{s g}_{c} * \text { nonwhite }_{c}\right)+{ }_{4}\left(\mathbf{s g}_{c} * \text { female }_{c} * \text { nonwhite }_{c}\right)+ \\
& { }_{1} \text { cohort }_{c}+{ }_{2} \text { cohort }_{c}^{2}+{ }_{3} \text { ue }_{c}+v_{c},
\end{aligned}
$$

where $c$ indexes cell and,

female $=1$ if the $c_{t h}$ cell is composed of females,

nonwhite $=1$ if the $c_{t h}$ cell is composed of dropouts who are nonwhite,

state $=1$ if the $c_{t h}$ cell is composed of dropouts who took the tests in New York,

$\boldsymbol{s} \boldsymbol{g}=$ a vector of 9 dummy variables indicating whether the $c_{t h}$ cell contains dropouts in score group 2 or score group 3 or ...up to score group 10

cohort $=0$ if individual $i$ is in the 1986 testing cohort (and thus has earnings measured in 1991), 1 if in the 1987 cohort, ..., and 4 if in the 1990 cohort, $^{5}$

${ }^{5}$ In preliminary data analyses we are unable to reject the null hypothesis that the earnings of white and nonwhite females are jointly equal in New York and Florida, once we allow for a 
$u e=$ the state unemployment rate in state $j$ and year $k$ for 18-30 year-olds with only a high school diploma, GED, or 0 to 11 years of schooling, and

$v=$ a mean zero error term, assumed to be uncorrelated with the other regressors.

The $\alpha$ 's, $\beta$ 's, and $\gamma$ 's in Equation 1 are parameters to be estimated. In particular, the $\alpha$ parameters answer our main research questions. We control for state effects by including a

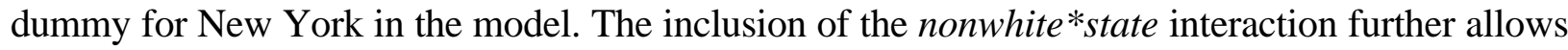
the earnings of nonwhite dropouts to be different across Florida and New York. ${ }^{6}$ We control for secular labor market trends in the years 1991-1995 by including the state-specific unemployment rates for 18-30 year-olds with a high school degree or less.

Because individuals in score groups 5-10 have a GED in both Florida and New York, while individuals in lower score groups do not (i.e., individuals in these score groups scored too low to pass the GED exams), the estimates on all of the parameters associated with score groups 5-10 measure the effect of skills on earnings plus any additional effect of the GED on earnings. ${ }^{7}$ By looking at the returns to skills within the 1-4 and the 5-10 groups separately, we can isolate the effect of skills on earnings from the impact of the GED credential on earnings.

\section{Estimation}

We do not know the population $\mu$ 's, but we possess the sample estimates, $\hat{\mu}$, provided by the Social Security Administration. We assume that

main effect of state on earnings and allow the earnings of all nonwhites to be different in the two states. We are also unable to reject the null hypothesis that the joint effect of all the score group dummies is the same across Florida and New York. Preliminary data analysis also indicates that the effect of being in the various cohorts is the same by gender and by race/ethnicity.

${ }^{6}$ We are unable to reject the null hypothesis that the earnings of white females are the same in the two states once we control for overall state effects $(\mathrm{p}=0.505)$, nor can we reject the null on a test that the joint effect of the score group dummies is the same in the two states $(\mathrm{p}=0.950)$.

${ }^{7}$ Tyler, Murnane, and Willett (1998) find an effect of the GED on earnings that is independent of the effect of cognitive skills for dropouts just at the margin of passing the exams. 


$$
\hat{\mu}_{c}=\mu_{c}+u_{c} \quad u_{c} \sim N\left(0,{ }^{2}\right)
$$

In our estimation we must account for the fact that the $\mu_{c}$ 's are estimated with varying precision.

We want to fit Equation 1, which we will represent here as:

$$
\mu_{c}=\boldsymbol{x}_{c}+v_{c},
$$

where $\boldsymbol{x}$ is a vector of the independent variables and is a vector of regression parameters to be estimated. However, because the $\mu_{c}$ are unknown we must instead fit the following model:

$$
\hat{\mu}_{c}=\boldsymbol{x}_{c}+\left(v_{c}+u_{c}\right)=\boldsymbol{x}_{c}+{ }_{c}
$$

Assuming that $u$ and $v$ are independent, that $E\left[\boldsymbol{v} \boldsymbol{v}^{\prime}\right]=\sigma^{2} \mathbf{I}$, and that

$$
E\left[u_{m} u_{n}\right]=\left\{\begin{array}{c}
2 \\
c, m=n \\
0, m \neq n
\end{array}, \quad \text { where } \quad c_{c}^{2}=\frac{2}{n_{c}},\right.
$$

with $n_{c}$ the cell frequency in the $c_{t h}$ cell, we have

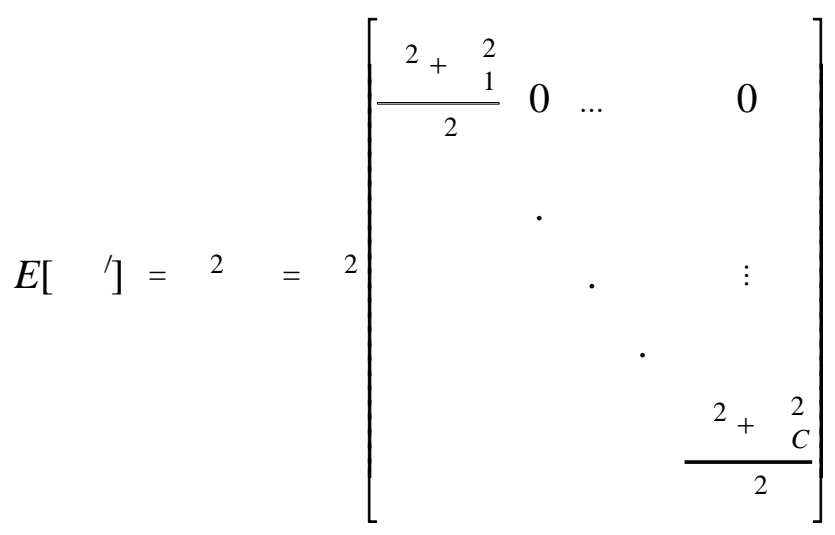


where $\mathrm{C}$ is the total number of cells.

Efficient estimation of in Equation (2) requires a consistent estimate of , which, in turn, requires estimates of each $\quad c_{c}^{2}$ and of ${ }^{2}$. Estimates of the $\quad_{c}^{2}$ are obtained by using the cell variances (supplied by the SSA) to estimate the ${ }_{c}^{2}$, in combination with the cell frequencies $n_{c}$ (also supplied by the SSA). Following Hanushek (1974), we use a two-step estimator for ${ }^{2}$. We then use our estimate of to form a Weighted Least Squares (WLS) fit of the model in Equation (1).

\section{Results}

Table 4 presents WLS estimates for the parameters of Equation (1). Given the parameterization of Equation (1), the estimate of the intercept in Table 4 indicates that the average annual earnings of young white male dropouts in score group 1 in Florida who tested in 1986 were about \$9,665. ${ }^{8}$ The earnings of comparable white females averaged about $\$ 4,200$ less than this, and those of nonwhite males in the same state, score group, and cohort were about \$1,240 less. Meanwhile, comparable nonwhite females earned about $\$ 3,300$ less $(-4190-1241+2129)$ than the baseline group. The estimate of the coefficients on the state and the nonwhite*state variables indicate that nonwhite dropouts tended to make about $\$ 659(121-780)$ less per year in New York than in Florida.

$<$ Table 4 about here>

As stated earlier, parameters answering our primary research questions are the coefficients associated with the score group dummies and with the score group-demographic group interactions. Since the relationship of the score groups to one another is monotonic, we should

${ }^{8}$ The effect of $u e$ (the unemployment rate) on this cohort in Florida would subtract another $\$ 731$ from this estimate. For ease and clarity of exposition we abstract away from this effect on earnings in this part of the discussion. 
see a pattern indicating that higher earnings are associated with higher score groups (except perhaps for the increment from score group 3 to score group 4). Looking down the list of estimated coefficients on the main-effect score group dummies, we see that in all but two cases this pattern holds true. ${ }^{9}$ Thus, for white males the pattern indicates that higher earnings are associated with higher GED scores. This pattern also holds for the other three demographic groups represented in the data: nonwhite males, white females, and nonwhite females. ${ }^{10}$

To clarify the returns to skills indicated by the estimates in Table 4, we tested a series of hypotheses regarding different score group-earnings relationships. First, we wanted to know if there was an overall increase in earnings associated with higher GED scores. To test this hypothesis, we compared the average earnings of individuals in the highest score groups (score groups 5-10) to the earnings of individuals in lowest score groups (groups 1-4). We chose these combinations of score groups because they represent a comparison of GED-holders versus nonGED holders. That is, as stated earlier, individuals in both states in score groups 5 and higher had scores high enough to be awarded a GED, while those in score groups 4 and lower failed the GED exams. To examine the overall returns to skills plus a GED for our sample of dropouts we conducted the following contrast for all four demographic groups,

$$
\left(\frac{\hat{y}_{10}+\hat{y}_{9}+\hat{y}_{8}+\hat{y}_{7}+\hat{y}_{6}+\hat{y}_{5}}{6}\right)-\left(\frac{\hat{y}_{4}+\hat{y}_{3}+\hat{y}_{2}+\hat{y}_{1}}{4}\right) \text {, }
$$

\section{Contrast 1}

where each $\hat{y}$ represents the estimated population mean earnings in the corresponding score group based on the estimates in Table 4. This contrast answers the question, do higher skilled young dropouts earn more on average than lower skilled young dropouts?

To analyze in greater detail the skill-earnings relationship, we examined potential returns to

${ }^{9}$ While the point estimate drops from score group 3 to score group 4 (1887 to 1205) and score group 9 to score group 10 (2839 to 2776), we are unable in each case to reject the null hypothesis that the estimates are equal.

${ }^{10}$ The only instance where there is a decline in the earnings-score group relationship between successively higher score groups and where we can reject the null of equality is between score groups 3 and 4 for white females. 
skills for the lowest-skilled dropouts in our data (those in score groups 1-4), as well as the returns to skills for the highest skilled dropouts (those in score groups 5-10). For the low-skilled dropouts we compared the earnings of those in score groups 3 and 4 with the earnings of those in score groups 1 and 2. For the high skilled dropouts we compared the earnings of those in score groups 8-10 with the earnings of dropouts in score groups 5-7. Those two contrasts were conducted in the following manner:

$$
\begin{gathered}
\left(\frac{\hat{y}_{4}+\hat{y}_{3}}{2}\right)-\left(\frac{\hat{y}_{2}+\hat{y}_{1}}{2}\right) \text { for low skilled dropouts } \\
\left(\frac{\hat{y}_{10}+\hat{y}_{9}+\hat{y}_{8}}{3}\right)-\left(\frac{\hat{y}_{7}+\hat{y}_{6}+\hat{y}_{5}}{3}\right) \text { for high skilled dropout }
\end{gathered}
$$

Contrast 2

Contrast 3

The results of these contrasts for the four demographic groups in our study, along with the pvalues from the relevant hypothesis tests for equality, are presented in Table 5.

\section{<Table 5 about here>}

Row 1 in Table 5 shows the results from Contrast 1, the difference between the average earnings of high skilled dropouts and those of low skilled dropouts, in each of the four demographic groups. The entries in this first row indicate that all four demographic subgroups realize substantial returns to higher GED scores, to acquisition of a GED, or to both.

Furthermore, these returns are greater for females than for males. ${ }^{11}$ Given the increase during the 1980s in the gap between the earnings of white males and those of black males (Bound and Freeman 1992), it is notable that the economic return to skills is larger for nonwhite males than

${ }^{11}$ We can reject the hypothesis that Contrast 1 for white males $=$ Contrast 1 for white females $(\mathrm{p}=0.000)$ and that Contrast 1 for nonwhite males $=$ Contrast 1 for nonwhite females $(\mathrm{p}=0.002)$. 
for white males. ${ }^{12}$

A second question addressed in Table 5 is whether or not young dropouts experience returns to skills even within more narrowly defined ranges of skills. Looking within more narrowly defined skill groups also has the advantage of allowing us to examine the returns to skills while controlling for the separate effect of GED acquisition on earnings. The second row of Table 5 shows the results from Contrast 2, the returns to skills for low skilled dropouts, and the third row gives the results from Contrast 3, the returns for high skilled dropouts. The results in these rows indicate that even within narrowly defined ranges, dropouts with higher GED scores experience higher earnings. Moreover, with two exceptions, the economic returns to small differences in measured skills are statistically significant and substantial, with higher scores translating into about $\$ 1,000$ to $\$ 1,400$ more per year in earnings. The two exceptions are Contrast 3 for white males and Contrast 2 for white females.

The next step is to formally examine differences in the returns to skills across the demographic groups. If we focus only on the inter-group contrasts that are statistically significant at the 0.05 level, the following patterns emerge. First, skills plus a GED (as captured in Contrast 1) matter more for females than for males and slightly more for nonwhites than for whites. The average difference between Contrast 1 for females and Contrast 1 for males indicates that the returns to skills plus a GED are about $\$ 1,200$ greater for females than for males. ${ }^{13} \mathrm{~A}$ similar comparison across race/ethnicity groups indicates that the average return to skills plus a GED is about $\$ 208$ greater for nonwhites than for whites. ${ }^{14}$

${ }^{12}$ We can reject the hypothesis that Contrast 1 for white males $=$ Contrast 1 for nonwhite males $(\mathrm{p}=0.008)$. We cannot reject the hypothesis that Contrast 1 for white females $=$ Contrast 1 for nonwhite females $(\mathrm{p}=0.339)$.

${ }^{13} \mathrm{p}=0.000$ in a test that the average of cells 1 and 2 equals the average of cells 3 and 4 in row 1.

${ }^{14} \mathrm{p}=0.000$ in a test that the average of cells 1 and 3 equals the average of cells 2 and 4 in row 1. Tyler, Murnane, and Willett (1998) find that, controlling for skills, GED acquisition is much more important for young white dropouts on the margin of passing than for young nonwhite dropouts on the margin of passing. Reconciliation of those results with the results in this current study means that: (1) the "gross" returns to skills for nonwhite dropouts are substantially higher than for white dropouts, (2) the returns to a GED for highly skilled nonwhite dropouts are greater 
The story regarding returns to low-level skills is somewhat different. The figures in row 2 of the table indicate that returns to low-level skills are about the same (approximately $\$ 1,000$ ) for all groups except for white females. ${ }^{15}$

Row 3 indicates that among higher skilled dropouts who all had a GED, higher scores means higher earnings for all groups except young white males. Also, among the three groups exhibiting statistically significant returns to higher skills, the returns are the greatest for nonwhite dropouts. ${ }^{16}$

In summary, three central stories emerge from an examination of the returns to skills within narrowly defined gender, race/ethnicity, and skill categories. First, among individuals in almost every demographic-skill group, greater cognitive skills as measured by GED exam scores led to substantially higher earnings five years later. The exceptions are the highest skilled white male dropouts and the lowest skilled white female dropouts. Second, we do not find that young nonwhite dropouts are being relegated to jobs where skills do not matter. In fact, even among the least skilled nonwhite male and female young dropouts, higher GED scores mean substantially higher earnings. Finally, not all GED holders are treated the same in the labor market. That is, except for white males, higher scoring GED holders earn substantially more than lower scoring GED holders, and the returns to skills are largest for young nonwhite GED holders.

A fair question is whether the patterns displayed in Table 5 are different across Florida and New York. In a model that includes all of the relevant state interactions, we can reproduce tables similar to Table 5 separately for the dropouts who attempted their GED in Florida and those who attempted their GED in New York. Doing this and comparing the twelve contrast by demographic group cells as represented in Table 5, we can reject the hypothesis that the relevant contrast in Florida equals the same contrast in New York in only two of the twelve instances. In particular, we can reject that Contrast 1 and Contrast 3 for nonwhite males in Florida and New York are

than the returns to similarly skilled white dropouts, or (3) both (1) and (2) are true.

${ }^{15}$ We reject the null in all comparisons with white females in row 2, and we cannot reject the null in any of the comparisons between the other three groups in row 2.

${ }^{16} \mathrm{p}=0.051$ on a test that the average of cells 2 and 4 equals cell 3 in row 3 . However, we cannot reject the nulls that cell 2 equals cell 3, that cell 4 equals cell 3 , or that jointly cells 2 and 4 equal cell 3 . 
equal. In each of these two contrasts, the returns for nonwhite males are higher in Florida than in New York. Thus, except perhaps for nonwhite males, Table 5 is a good representation of the returns to skills five years after last taking the GED exams for young dropouts in both Florida and New York in the first half of the 1990s. ${ }^{17}$

One final question of interest concerns the importance of age. Would the returns to skill be the same if earnings were measured when the dropouts were younger? To answer this question, we replicated our analyses using as the dependent variable annual earnings (in 1995 dollars) one year after the dropouts in the sample last took the GED exams. Table 6, which is identical in structure to Table 5, provide a summary of the results. Just as when the dropouts were four years older (Table 5), skill differences are associated with statistically significant earnings differences in all but two of the contrasts. However, the magnitudes of the earnings differences associated with skill differences are, on average, about half as large among 17-22 year-old dropouts as they are among the same groups when they are four years older. That the returns to cognitive skills increase with age is a pattern also found in other studies (Altonji and Pierret 1996; Farber and Gibbons 1996).

\section{Conclusion}

This study uses a unique, new data set to examine the relationship between the skills that young dropouts bring to the labor market and their annual earnings. Our results, based on the earnings of 21-26 year-old dropouts who attempted the GED exams in Florida and New York in the years 1986 to 1990, have both discouraging and encouraging elements as we think about the labor market prospects of young dropouts in the 1990s.

First, our data show that the average annual earnings levels of young dropouts are quite low. Average unconditional earnings for males range from a low of \$9,394 in New York in 1995 to a

${ }^{17}$ The two entries for which we can reject the null of equality between the states suggest the following situation: nonwhite males in Florida enjoy higher overall returns to skills than nonwhite males in New York because more highly skilled nonwhite males in Florida have significantly greater returns than do more highly skilled nonwhite males in New York. 
high of $\$ 10,869$ in Florida in 1995 . The comparable figures for females are a low of $\$ 6,886$ in New York in 1995 and a high of \$7,955 in Florida in 1994. Since these averages contain zero earnings for individuals who did not work in a year, they represent the combined effect of wages and labor supply on earnings.

More encouraging news is that for whites and nonwhites, males and females, skills are an important determinant of earnings. Our results show that in the labor market of the early 1990s, young high school dropouts could expect higher annual earnings if they had higher levels of basic cognitive skills. Our results also show inter-group variation in the returns to skills, with females generally having higher returns than males, and nonwhites, especially high skilled nonwhites, having greater returns than white dropouts.

The significant economic return to modest skill differences among nonwhite male dropouts sheds light on a puzzle in the random-assignment evaluation of the Perry Pre-School Program. As Barnett (1996) has described, black males who participated in the early childhood intervention program did not have greater educational attainments, on average, then did black males in the control group. Yet, the black males in the treatment group did have somewhat higher average earnings at age 27 than did black males in the control group. Barnett speculated that this may have stemmed from the higher average cognitive skills of the treatment group, as measured by test scores during their schooling years. The evidence presented in this paper on the economic returns to skill differences for nonwhite male dropouts supports Barnett's hypothesis.

Welfare reform is pushing many low-skilled individuals into a labor market where skills increasingly matter. Our research, which measures skills with a high-stakes test (the GED exams) and earnings with reliable administrative data (Social Security earnings), shows that higher cognitive skills mean higher subsequent earnings for dropouts. This is the good news. However, while our estimates of the returns to skills for many groups are large in percentage terms, we caution that this is largely because these young dropouts have such low average annual earnings to begin with. This is the bad news, and it is a strong argument against a decision to drop out in the first place. 
Figure 1. GED score groups formed from combinations of minimum and mean scores.

\begin{tabular}{lll} 
Minimum & \multicolumn{2}{c}{ Mean Score } \\
\cline { 2 - 3 } Score & \multicolumn{2}{c}{$>=45$} \\
\hline $20-34$ & Scoregrp 1 & \\
$35-39$ & Scoregrp 2 & Scoregrp 4 \\
$40-44$ & Scoregrp 3 & Scoregrp 5 \\
$45-46$ & & Scoregrp 6 \\
$47-48$ & & Scoregrp 7 \\
$49-50$ & & Scoregrp 8 \\
$51-52$ & & Scoregrp 9 \\
$53+$ & & Scoregrp 10 \\
\hline \hline
\end{tabular}


Table 1. Proportion of GED testers age 16-21 who attempted the battery in the years 1986-1990 in Florida and New York, by gender, race, and GED score group.

\begin{tabular}{lll}
\hline & FL & NY \\
\hline Proportion who are... & & \\
in .. & 0.46 & 0.53 \\
male & 0.55 & 0.56 \\
white & 0.76 & 0.57 \\
Proportion in... & & \\
Score group 1 & 0.04 & 0.06 \\
Score group 2 & 0.07 & 0.09 \\
Score group 3 & 0.03 & 0.04 \\
Score group 4 & 0.007 & 0.01 \\
Score group 5 & 0.32 & 0.33 \\
Score group 6 & 0.14 & 0.13 \\
Score group 7 & 0.11 & 0.10 \\
Score group 8 & 0.10 & 0.08 \\
Score group 9 & 0.08 & 0.06 \\
Score group 10 & 0.12 & 0.10 \\
\hline \hline
\end{tabular}


Table 2. Mean earnings (1995 \$), for young male dropouts by state and year (1991-1995).

\begin{tabular}{lrrrrr}
\hline & \multicolumn{5}{c}{ Year Earnings Measured } \\
\cline { 2 - 6 } State & 1991 & 1992 & 1993 & 1994 & 1995 \\
\hline \multirow{2}{*}{ FL } & 10710 & 10445 & 10545 & 10477 & 10869 \\
& & & & & \\
NY & 10629 & 9985 & 9807 & 9916 & 9394 \\
& & & & & \\
\hline \hline
\end{tabular}

Table 3. Mean earnings (1995 \$), for young female dropouts by state and year (1991-1995).

\begin{tabular}{lccccc} 
& \multicolumn{5}{c}{ Year Earnings Measured } \\
\cline { 2 - 6 } State & 1991 & 1992 & 1993 & 1994 & 1995 \\
\hline FL & 7875 & 7735 & 7833 & 7955 & 7707 \\
& & & & & \\
NY & 7896 & 7600 & 7301 & 7172 & 6886 \\
\hline \hline
\end{tabular}


Table 4. Weighted-least-squares estimates of Equation (1).

(Standard errors in parentheses with $\mathrm{p}<0.10=\sim$, $\mathrm{p}<0.05=*$ and $\mathrm{p}<0.01=* *$. Estimates are over 635 cells containing 174,125 individual observations.)

$\begin{array}{ccc}\text { female } * \text { score group } & \text { nonwhite } * \text { score group } & \text { female }^{*} \text { nonwhite } \\ \text { interactions } & \text { interactions } & \text { score group } \\ & \text { interactions }\end{array}$

\begin{tabular}{|c|c|c|c|c|}
\hline intercept & $\begin{array}{c}9665^{* * *} \\
(380)\end{array}$ & & & \\
\hline female & $\begin{array}{c}-4190 * * \\
(306)\end{array}$ & & & \\
\hline nonwhite & $\begin{array}{c}-1241 * * \\
(312)\end{array}$ & & & \\
\hline state & $\begin{array}{c}121 \\
(105)\end{array}$ & & & \\
\hline nonwhite*female & $\begin{array}{c}2129 * * \\
(420)\end{array}$ & & & \\
\hline nonwhite ${ }^{*}$ state & $\begin{array}{c}-781 * * \\
(132)\end{array}$ & & & \\
\hline score group 2 & $\begin{array}{c}1068^{* *} \\
(299)\end{array}$ & $\begin{array}{l}-193 \\
(41)\end{array}$ & $\begin{array}{l}-393 \\
(417)\end{array}$ & $\begin{array}{c}404 \\
(572)\end{array}$ \\
\hline score group 3 & $\begin{array}{c}1887 * * \\
(335)\end{array}$ & $\begin{array}{l}-708 \\
(450)\end{array}$ & $\begin{array}{l}-883^{\sim} \\
(480)\end{array}$ & $\begin{array}{l}1154^{\sim} \\
(647)\end{array}$ \\
\hline score group 4 & $\begin{array}{l}1205^{*} \\
(467)\end{array}$ & $\begin{array}{c}-1132^{\sim} \\
(612)\end{array}$ & $\begin{array}{c}411 \\
(702)\end{array}$ & $\begin{array}{l}1106 \\
(937)\end{array}$ \\
\hline score group 5 & $\begin{array}{c}2358 * * \\
(257)\end{array}$ & $\begin{array}{c}502 \\
(357)\end{array}$ & $\begin{array}{l}-535 \\
(360)\end{array}$ & $\begin{array}{c}547 \\
(499)\end{array}$ \\
\hline score group 6 & $\begin{array}{c}2554 * * \\
(275)\end{array}$ & $\begin{array}{l}726^{\sim} \\
(382)\end{array}$ & $\begin{array}{l}-138 \\
(400)\end{array}$ & $\begin{array}{c}-42 \\
(555)\end{array}$ \\
\hline score group 7 & $\begin{array}{c}2717 * * \\
(279)\end{array}$ & $\begin{array}{l}934 * \\
(387)\end{array}$ & $\begin{array}{c}234 \\
(416)\end{array}$ & $\begin{array}{c}-42 \\
(582)\end{array}$ \\
\hline score group 8 & $\begin{array}{c}2474 * * \\
(285)\end{array}$ & $\begin{array}{c}1464 * * \\
(394)\end{array}$ & $\begin{array}{c}596 \\
(437)\end{array}$ & $\begin{array}{l}-281 \\
(615)\end{array}$ \\
\hline score group 9 & $\begin{array}{c}2839 * * \\
(301)\end{array}$ & $\begin{array}{c}1395 * * \\
(416)\end{array}$ & $\begin{array}{l}1168 * \\
(488)\end{array}$ & $\begin{array}{l}-860 \\
(685)\end{array}$ \\
\hline score group 10 & $\begin{array}{c}2776 * * \\
(284)\end{array}$ & $\begin{array}{c}1716^{* * *} \\
(397)\end{array}$ & $\begin{array}{c}1171 * * \\
(441)\end{array}$ & $\begin{array}{l}-420 \\
(630)\end{array}$ \\
\hline
\end{tabular}




\begin{tabular}{lc} 
cohort & $-245^{* *}$ \\
& $(81)$ \\
& $33^{\sim}$ \\
cohort $^{2}$ & $(19)$ \\
& $-62^{*}$ \\
$u e$ & $(25)$ \\
\hline \hline
\end{tabular}


Table 5. Earnings contrasts across skill levels by demographic group, five years after last taking GED exams. ( $\mathrm{p}$-values for the relevant F-tests within parentheses, and $\mathrm{p}<0.01==^{* *}, \mathrm{p}<0.05=*$.)

\begin{tabular}{lcccc}
\hline & \multicolumn{4}{c}{ Contrast Estimates } \\
\cline { 2 - 5 } & white males & nonwhite males & white females & nonwhite females \\
\hline $\begin{array}{l}\text { Contrast } 1 \\
\text { "gross" returns to } \\
\text { skills }+ \text { GED }\end{array}$ & $\begin{array}{c}1580^{* *} \\
(\mathrm{p}=0.000)\end{array}$ & $\begin{array}{c}2212^{* *} \\
(\mathrm{p}=0.000)\end{array}$ & $\begin{array}{c}3211^{* *} \\
(\mathrm{p}=0.000)\end{array}$ & $\begin{array}{c}2995^{* *} \\
(\mathrm{p}=0.000)\end{array}$ \\
$\begin{array}{l}\text { Contrast } 2 \\
\text { returns to low-level } \\
\text { skills }\end{array}$ & $\begin{array}{c}1012^{* *} \\
(\mathrm{p}=0.000)\end{array}$ & $\begin{array}{c}973^{* *} \\
(\mathrm{p}=0.002)\end{array}$ & $\begin{array}{c}189 \\
(\mathrm{p}=0.438)\end{array}$ & $\begin{array}{c}1078^{* *} \\
\text { Contrast 3 } \\
\text { returns to high-level } \\
\text { skills }\end{array}$ \\
\hline \hline
\end{tabular}

The F-test in Contrast 1 is whether $\frac{\hat{y}_{10}+\hat{y}_{9}+\hat{y}_{8}+\hat{y}_{7}+\hat{y}_{6}+\hat{y}_{5}}{6}=\frac{\hat{y}_{4}+\hat{y}_{3}+\hat{y}_{2}+\hat{y}_{1}}{4}$ within group.

The F-test in Contrast 2 is whether $\frac{\hat{y}_{4}+\hat{y}_{3}}{2}=\frac{\hat{y}_{2}+\hat{y}_{1}}{2}$ within group.

The F-test in Contrast 3 is whether $\frac{\hat{y}_{10}+\hat{y}_{9}+\hat{y}_{8}}{3}=\frac{\hat{y}_{7}+\hat{y}_{6}+\hat{y}_{5}}{3}$ within group.

Table 6. Earnings contrasts across skill levels by demographic group, one year after last taking GED exams

\begin{tabular}{lcccc}
\hline & \multicolumn{4}{c}{ Contrast Estimates } \\
\cline { 2 - 5 } & white males & nonwhite males & white females & nonwhite females \\
\hline $\begin{array}{l}\text { Contrast 1 } \\
\text { "gross" returns to } \\
\text { skills + GED }\end{array}$ & $\begin{array}{c}557^{* *} \\
(\mathrm{p}=0.000)\end{array}$ & $\begin{array}{c}692^{* *} \\
(\mathrm{p}=0.000)\end{array}$ & $\begin{array}{c}1726^{* *} \\
(\mathrm{p}=0.000)\end{array}$ & $\begin{array}{c}1326^{* *} \\
(\mathrm{p}=0.000)\end{array}$ \\
$\begin{array}{l}\text { Contrast 2 } \\
\text { returns to low-level } \\
\text { skills }\end{array}$ & $\begin{array}{l}694^{* *} \\
(\mathrm{p}=0.000)\end{array}$ & $\begin{array}{c}491^{* *} \\
(\mathrm{p}=0.030)\end{array}$ & $\begin{array}{c}334^{*} \\
(\mathrm{p}=0.070)\end{array}$ & $\begin{array}{c}543^{* *} \\
(\mathrm{p}=0.010)\end{array}$ \\
$\begin{array}{l}\text { Contrast 3 } \\
\text { returns to high-level } \\
\text { skills }\end{array}$ & \begin{tabular}{l}
$7 \mathrm{p}=0.830)$ \\
\hline \hline
\end{tabular} & $\begin{array}{c}774^{* *} \\
(\mathrm{p}=0.000)\end{array}$ & $\begin{array}{c}450^{* *} \\
(\mathrm{p}=0.000)\end{array}$ & $\begin{array}{c}999^{* *} \\
(\mathrm{p}=0.000)\end{array}$ \\
\hline
\end{tabular}




\section{References}

Altonji, Joseph G., and Charles R. Pierret. "Employer Learning and the Signaling Value of Education." . Cambridge, MA: National Bureau of Economic Research Working Paper \#5438, 1996.

Angrist, Joshua D. "Estimating the Labor Market Impact of Voluntary Military Service Using Social Security Data on Military Applicants." Econometrica 66, no. 2 (1997): 249-88.

Barnett, W. Steven. Lives in the Balance: Age-27 Benefit-Cost Analysis of the High/Scope Perry Preschool Program. Vol. 11 Monographs of the High/Scope Educational Research Foundation. Ypsilanti, MI: The High/Scope Press, 1996.

Bound, John, and Richard F. Freeman. "What Went Wrong? The Erosion of Relative Earnings and Employment Among Young Black Men in the 1980s." Quarterly Journal of Economics February (1992): 201-232.

Farber, Henry S., and Robert Gibbons. "Learning and Wage Dynamics." Quarterly Journal of Economics November (1996): 1007-1047.

Hanushek, Eric A. "Efficient Estimators for Regressing Regression Coefficients." The American Statistician 28, no. 2 (1974): 66-67.

Tyler, John H., Richard J. Murnane, and John B. Willett. "Estimating the Impact of the GED on the Earnings of Young Dropouts Using a Series of Natural Experiments." . Cambridge, MA: National Bureau of Economic Research Working Paper \#6391, 1998. 